\title{
Observations and analysis of a 63-year-old reinforced concrete promenade railing exposed to the North Sea
}

\author{
R. E. Melchers*, C. Q. Li† and M. A. Davison† \\ The University of Newcastle; University of Greenwich; Infrastructure Services
}

\begin{abstract}
Despite being exposed to the harsh sea-spray environment of the North Sea at Arbroath, Scotland, for over 63 years, many of the reinforced concrete precast beam elements of the $1.5 \mathrm{~km}$ long promenade railing are still in very good condition and show little evidence of reinforcement corrosion. In contrast, railing replacements constructed in about 1968 and in 1993 are almost all badly cracked as a result of extensive corrosion of the longitudinal reinforcement. This is despite the newer concrete appearing to be of better quality than the 1943 concrete. Statistics for maximum crack width for each of the three populations, based on measurements made in 2004 and in 2006, are presented. In situ and laboratory measurements show that the 1943 concrete appears to have high permeability but it also shows high electrical resistivity. Chloride penetration measurements show the 1943 and 1993 concretes to have similar chloride profiles and similar chloride concentrations at the reinforcement bars. This is inconsistent with the 1943 beams showing much less reinforcement corrosion than their later replacements and casts doubt on the conventional practice for durability design focusing on reducing concrete permeability through denser concretes or greater cover.
\end{abstract}

\section{Introduction}

There is widespread acceptance that corrosion of reinforcing bars is related to the aggressive nature of chlorides diffused through the concrete cover (and perhaps by means of pathways involving concrete cracks), with higher chloride concentration levels and faster diffusion causing earlier corrosion initiation. This effect tends to be opposed by the presence of a sufficient concentration of hydroxide ions, although the precise mechanisms involved have thus far remained elusive. ${ }^{1}$ One indication of this is that the critical ratio of chloride to hydroxide ions for defining initiation of corrosion has remained poorly understood, with acceptance levels defined largely arbitrarily. ${ }^{2}$ Some isolated cases have been reported of no apparent occurrence of corrosion even after long exposure periods ${ }^{3}$ even in normally

\footnotetext{
* Centre for Infrastructure Performance and Reliability, The University of Newcastle, Australia

$\dagger$ Department of Civil Engineering, The University of Greenwich, UK Infrastructure Services, Angus Council, Scotland, UK
}

(MACR-D-07-00093) Paper received 10 August 2007; last revised 27 March 2008; accepted 18 July 2008 highly aggressive environments. ${ }^{4}$ On the other hand, there is also evidence of corrosion initiation even after relatively short periods of exposure. Moreover, laboratory experimental evidence has shown that although corrosion initiation can occur quite early, there may not be continued active corrosion until much later. ${ }^{5,6}$

For marine environments the chlorides present in seawater usually are considered as the cause of reinforcement corrosion. ${ }^{2}$ Despite some evidence to the contrary, ${ }^{4}$ it is also accepted that durable reinforced concretes for these environments require considerable amounts of concrete cover to the reinforcement and high-density (quality) concretes to slow down the inward diffusion of chlorides from the surrounding environment (and by implication the loss of hydroxides to the external environment). Admixtures have been advocated widely as appropriate to creating less permeable concretes for the same purpose. These features (thick cover, dense concretes) were, however, seldom achieved in older reinforced concretes, many of which would be considered by modern standards to be of inferior strength and quality.

Relatively few older reinforced concrete structures exposed to marine exposure conditions are available for 
detailed investigation, ${ }^{4,7-11}$ and even fewer that permit direct comparison to more recent concretes. One such opportunity was found to be available at Arbroath, Scotland. Immediately north of the town centre there is a $1.5 \mathrm{~km}$ long reinforced concrete promenade railing immediately adjacent to and exposed to open North Sea waters (Fig. 1). It is known that, particularly during winter storm conditions, seawater washes over the railing and the adjacent concrete pathway.

The railing consists of 244 nominally identical sections each composed of four precast concrete railing beams set in cast-in-situ posts of alternating widths of $300 \mathrm{~mm}$ and $600 \mathrm{~mm}$ (Fig. 2). Each individual railing beam is approximately $2.04 \mathrm{~m}$ long between posts and has a chamfered cross-section nominally $130 \mathrm{~mm}$ wide $\times 150 \mathrm{~mm}$ in height. Fig. 3 shows the typical crosssections and some typical crack patterns.

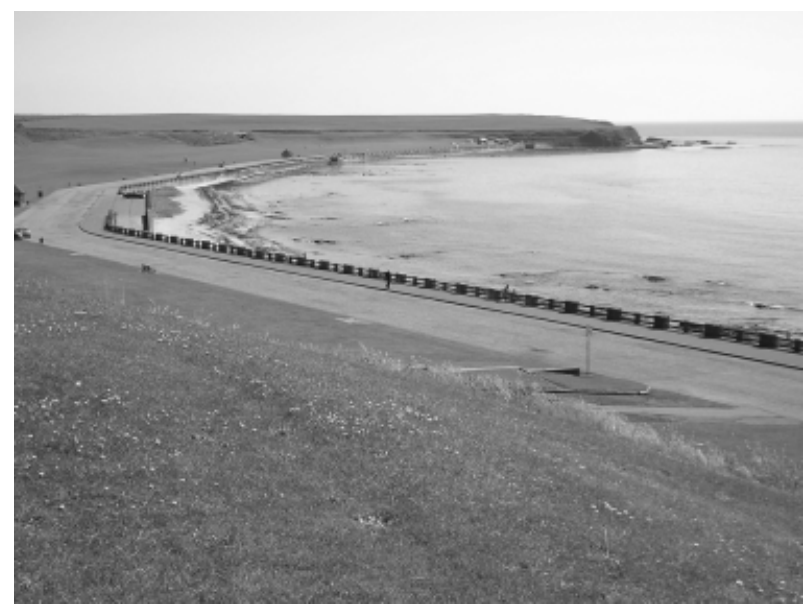

Fig. 1. Overview of reinforced concrete promenade railing at Arbroath, Scotland, facing the North Sea. The railing commences just to the left of the headland

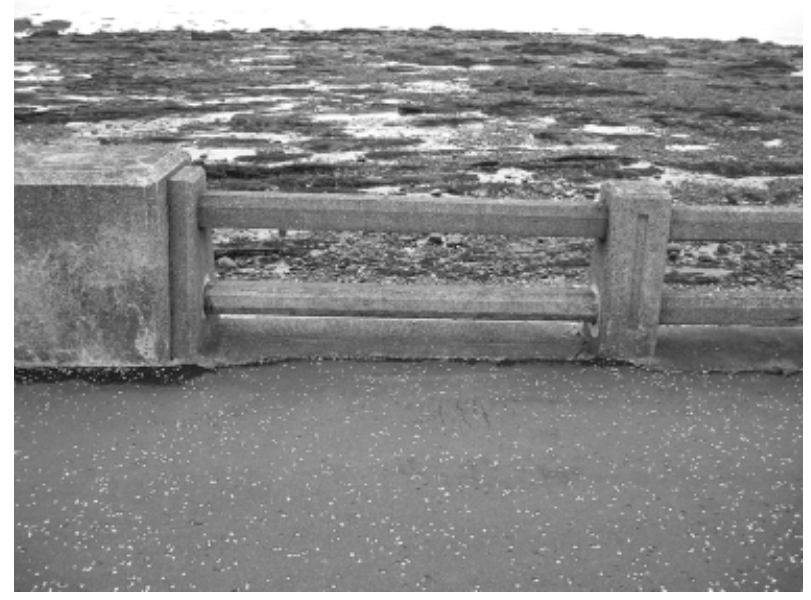

Fig. 2. Typical (part-)section of the reinforced concrete promenade railing showing the four precast railing beams, the cast-in-situ central support and the left end-post. The railing beam identification is used in Table 1. Water level is low tide

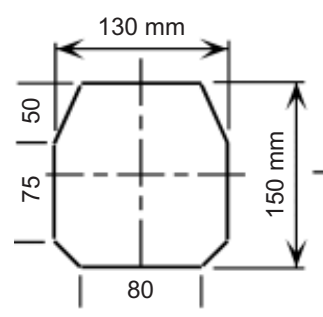

(a)

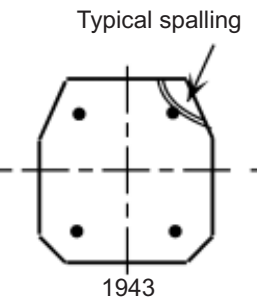

(b)

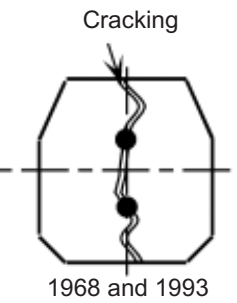

(c)
Fig. 3. (a) Schematic cross-sections; and reinforcement layout and typical crack patterns for (b) the 1943 and (c) the 1968 and 1993 railing beams. In all cases the nominal concrete cover to the reinforcement is about $25 \mathrm{~mm}$

The promenade railing was initially constructed in 1943. As part of the present investigation it has been estimated that fewer than $1 \%$ of the railings were replaced during 1968 and it is known that about 10\% were replaced in 1993 (these may have included some 1968 replacements). Owing to local and regional council restructuring, some of the documentation for the original construction work in 1943, the condition of the balustrade in 1968 and the reasons for repair at that time and the construction details are unavailable. It is, however, reasonable to assume that there were problems with reinforcement corrosion of a small proportion of the balustrade already in the mid-1960s and that this also prompted the replacement work in 1993.

Field inspection showed (and subsequent laboratory observations confirmed) that the 1943 beams contain four $6 \mathrm{~mm}$ diameter bars (Fig. 3) with a nominal (but highly variable) cover of about $20-25 \mathrm{~mm}$. There are only a few 1968 beams remaining, but these appear from field inspection to have only two bars of nominally $13 \mathrm{~mm}$ diameter placed along the vertical central longitudinal axis (Fig. 3). Drawings available for the 1993 beams show that these are similar to the 1968 beams but that the bars were coated with a commercial zinc-rich primer. Also, the concrete used in the 1993 beams was air-entrained in an effort to counter perceived problems with freeze-thaw behaviour.

It was considered that the repetitive nature of the construction of the promenade railing at Arbroath, its high level of exposure to the aggressive North Sea environment and the fact that there have been two replacement schemes at approximately 25-year intervals presented an opportunity to obtain statistical data on reinforcement corrosion effects. As will be seen, it has also provided an opportunity to obtain some further insight regarding reinforcement corrosion in a marine environment. This is the purpose of the present paper.

\section{Condition survey}

The structure was surveyed in detail during the autumn of 2004 and again two years later during the autumn of 2006. Overall condition and crack size, length and depth were measured and concrete blistering 
and spalling, exposed reinforcement and repairs (patching) were noted. Table 1 presents an abbreviated summary of the observations.

Close visual examination of the surface texture of the three types of beams shows remarkable differences. The 1943 beams all show a characteristic rough surface, some signs of external wear and some deterioration of once sharp edges (Fig. 4). These beams appear to have been constructed using aggregates of widely varying size (Fig. 5). Close inspection shows the concrete to contain a significant proportion of crushed seashells, identified both by their characteristic shapes and through testing with a very fine application of hydrochloric acid. Once this characteristic was identified it allowed ready identification and differentiation of the 1943 beams from the later beams.

Only some $2 \%$ of the 1943 railings in existence in 2006 showed minor (hairline) cracking and minor local spalling. In contrast, most of the replacement reinforced concrete railings are badly cracked longitudinally. There is clear evidence within the cracks of very heavy corrosion of the reinforcement steel (Fig. 6).

The exterior surfaces of both the 1968 and the 1993 replacement concrete beams are generally of smooth and dense surface texture, indicating an apparently well-graded concrete mix at the surfaces. They also show sharp edges, indicating a good-quality concrete. Rebound hammer tests were carried out at three locations (centre and towards the ends of each beam) on surfaces rubbed smooth using a carborundum stone for randomly selected samples of each beam type. The results (Table 2) were found to be consistent with the superficial observation of surface density for the 1943 and 1968 beams. The 1993 beams were, however, found to have lower than expected rebound results. This may be consistent with the use of an air-entraining agent for the 1993 concrete as this lowers concrete density and is known to affect rebound hammer results. ${ }^{12}$ Microscopy observations of the 1993 concrete showed a considerable number of voids (Fig. 7), consistent with the use of an air-entrainment agent and also consistent with a lower concrete density.

Visual observation of the 1943 beams showed some localised blistering and spalling of the concrete cover but no serious cracking such as seen for the later beams. Hairline cracks offset from the centreline were observed (Figs 3 and 8). These are likely to be the direct result of the corrosion of the $6 \mathrm{~mm}$ reinforcing bars relatively close to the exterior surface (Fig. 3). Only some 5\% of the 1943 beams showed localised patch repairs and many exhibited some degree of minor rust staining on the exterior surfaces (Fig. 8). Collectively these observations suggest that, while very localised corrosion initiation had occurred for many of the 1943 beams, by 2006 it had not progressed to the stage of inducing spalling of the concrete cover. This is some 63 years after construction.

In contrast, most of the 1968 and 1993 replacement beams showed severe longitudinal cracking with very large crack openings (Fig. 5). Only some $25 \%$ of these beams remained uncracked in 2006. Moreover, there was very little longitudinal cracking of small sizemuch less than would be expected according to the standard bi-linear damage model that predicts a gradual increase in damage of reinforced concrete with time after reinforcement corrosion initiation. ${ }^{2}$

\section{Crack statistics}

Maximum crack size as a function of period of exposure and year of construction is an important criterion for structural performance. Fig. 9 shows a histogram of crack sizes. It is clear that the 1943 beams show a much lower overall crack size distribution and also have a very high proportion of uncracked beams. In contrast, the 1968 and 1993 replacement beams have a very substantial number of cracks of large sizes. Given the wide disparity of the respective corrosion and cracking behaviours and the large sample sizes involved, it is highly unlikely that such differences are owing to randomness as has been suggested may be possible for reinforced concrete structures in general. ${ }^{13}$

From the condition survey (Table 1) it may be deduced that of the 22 sections (i.e. 88 beams) reconstructed in 1993, only 22 beams had survived to 2006 without significant cracking. Comparison between the 2004 and the 2006 surveys shows that about nine beams failed during that time, all dating from 1993. This represents an annual failure rate of about $0.5 \%$ at 2006. The failure of 66 beams from 1993 to 2006 suggests that the remaining 22 beams could be expected to fail in 3-5 years - that is, by 2010 or so.

For the two beams still remaining from 1968, it is similarly estimated that these can be expected to have failed by about 2008. Thus it is expected that by 2010 all the replacement beams will have failed. The failure rate from then on will be that for the 1943 beams. This can be estimated from the period 1993-2006 if it is assumed (reasonably, because as noted no records are available) that in 1993 all defective beams, both from 1943 and from 1968, were replaced. There would then have been no defective beams left in 1993 and all failures evident in 2004 and 2006 date from that time. In the period 1993-2006 some 24 beams constructed in 1943 failed, which is a failure rate of just under two per year (or about 0.2\%). Similarly, for the 1968 beams, 11 failed in the period 1993-2006, which represents a failure rate of less than one per year. To arrive at these estimates, it has been assumed that corrosion rate of reinforcement is constant with time after active corrosion has commenced - that is, as used in the common conventional bi-linear damage model for damage resulting from reinforcement corrosion in concrete structures. The model and its limitations have been reviewed earlier. ${ }^{1,2}$ 
岕 Table 1. Arbroath data summary: 2003 and 2006

\begin{tabular}{|c|c|c|c|c|c|c|c|c|}
\hline \multirow{2}{*}{ Bay No. } & \multirow{2}{*}{$\begin{array}{l}\text { Alternative } \\
\text { No. }\end{array}$} & \multirow[t]{2}{*}{ Origin year } & \multicolumn{4}{|c|}{ Crack, $x(y): \mathrm{mm}$} & \multirow[t]{2}{*}{ Observations 2003} & \multirow[t]{2}{*}{ Observations 2006} \\
\hline & & & A & B & $\mathrm{C}$ & $\mathrm{D}$ & & \\
\hline- & $1-4$ & 1943 & - & - & - & - & Typical & See footnote \\
\hline $1-10$ & $5-14$ & 1943 & - & - & - & - & Typical & \\
\hline 11 & 15 & 1993 & 5 & 7 & 8 & 7 & Cracks to rebar depth & - \\
\hline 12 & 16 & 1993 & - (h) & 6 & 6 & & & - \\
\hline 13 & 17 & 1993 & $3-7(3)$ & $3-7(4)$ & $3-7(5)$ & $3-7(3)$ & Ditto. Some rust staining & - \\
\hline 14 & 18 & 1993 & $3-7(3)$ & $3-7(3)$ & $3-7(3)$ & $3-7(4)$ & - & - \\
\hline 15 & 19 & 1993 & - & - & - & - & - & Section demolished \\
\hline 16 & 20 & 1993 & - & - & (2) & - & Slight hairline cracks & Hairline cracking A, B, D \\
\hline $17-19$ & $21-23$ & 1943 & - & - & - & - & Typical & - \\
\hline 20 & 24 & 1943 & - & - & - & - & Typical & A rust staining. D spalling \\
\hline 21 & 25 & 1993 & - & $3(5)$ & 6 & $6(2)$ & D: crack only at the bottom & - \\
\hline 22 & 26 & 1993 & - & $4(6)$ & 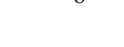 & $5(7-8)$ & Similar to other 1993 beams & - \\
\hline 23 & 27 & 1993 & $10(*)$ & $8(*)$ & $10(9)$ & $-(0.5)$ & - & - \\
\hline 24 & 28 & 1993 & $10(5-7)$ & $10(8)$ & $19(8)$ & $12(8)$ & Rust staining & - \\
\hline $25-40$ & $29-44$ & 1943 & - & - & - & - & Typical & 28, 39: side cracks \\
\hline 41 & 45 & 1993 & - & - & (5) & - & In good condition for 1993 & - \\
\hline $42-46$ & $46-50$ & 1943 & - & - & - & - & Typical & Alt50A $1 \mathrm{~mm}$ side \\
\hline 47 & 51 & 1993 & $8(10)$ & $8(9)$ & $3(6)$ & $12(10)$ & Cracks to rebar & - \\
\hline 48 & 52 & 1993 & $12(13)$ & $15(9)$ & $10(7)$ & $20(10+)$ & Ditto & - \\
\hline $49-56$ & $53-60$ & 1943 & - & - & - & - & Typical & - \\
\hline 57 & 61 & 1968/93? & $5(*)$ & $12(13)$ & $10(11)$ & $10(11)$ & Heavy rust staining & - \\
\hline 58 & 62 & 1943 & - & - & - & - & Good condition & Slight hairline cracks \\
\hline 59 & 63 & $1993 ?$ & - & 10 & - & - & Others OK & - \\
\hline 60 & 64 & 1993 & $12(10)$ & $15(*)$ & $12(7+)$ & $12(6+)$ & Heavy rust staining at cracks & - \\
\hline 61 & 65 & 1993 & 5 & 5 & 6 & 10 & As others & - \\
\hline 62 & 66 & 1993 & $3(*)$ & $3(*)$ & $3(3.5)$ & $5(*)$ & Ditto & - \\
\hline 63 & 67 & 1993 & $10(*)$ & $(*)$ & $5(6)$ & (h) & B collapsed, D in good condition & - \\
\hline 64 & 68 & 1993 & - & (3) & $5(7)$ & (4) & - & - \\
\hline $65-78$ & 69-83(a) & 1943 & - & - & - & - & Typical & $79 \mathrm{~A}\left({ }^{*}\right), \mathrm{B}(*) ; \mathrm{C}, \mathrm{D}$ cracked \\
\hline 79 & 84 & 1993 & $10(*)$ & $7(*)$ & $2(3)$ & $2(3)$ & & - \\
\hline $80-83$ & $85-88$ & 1943 & - & - & - & - & Typical & - \\
\hline 84 & 89 & 1943 & $(*)$ & - & - & - & Typical & ' 82 ' painted on pavement. Beam A cut out \\
\hline $85-86$ & $90-91$ & 1943 & - & - & - & - & Typical & since 2003; cross-sections sampled for $\mathrm{pH}$ \\
\hline & 92 & 1993 & $4(8)$ & $1(*)$ & $4(6)$ & $4(7)$ & - & - \\
\hline 88-101 & $93-106$ & 1943 & - & & & & Typical & - \\
\hline 102 & 107 & 1993 & $10(*)$ & $2(*)$ & $3(4)$ & $-(2)$ & & 102 painted on pavement \\
\hline $103-112$ & - & 1943 & - & - & - & - & 103AB, 107C $1-2 \mathrm{~mm}$ cracks & \\
\hline 113 & - & 1968 & $5(5)$ & $7(8)$ & $3(5)$ & $10(9)$ & Rebar visible in cracks & 113 painted on pavement \\
\hline $114-117$ & - & 1943 & - & - & - & - & 115B $1-2 \mathrm{~mm}$ crack $200 \mathrm{~mm}$ & - \\
\hline
\end{tabular}




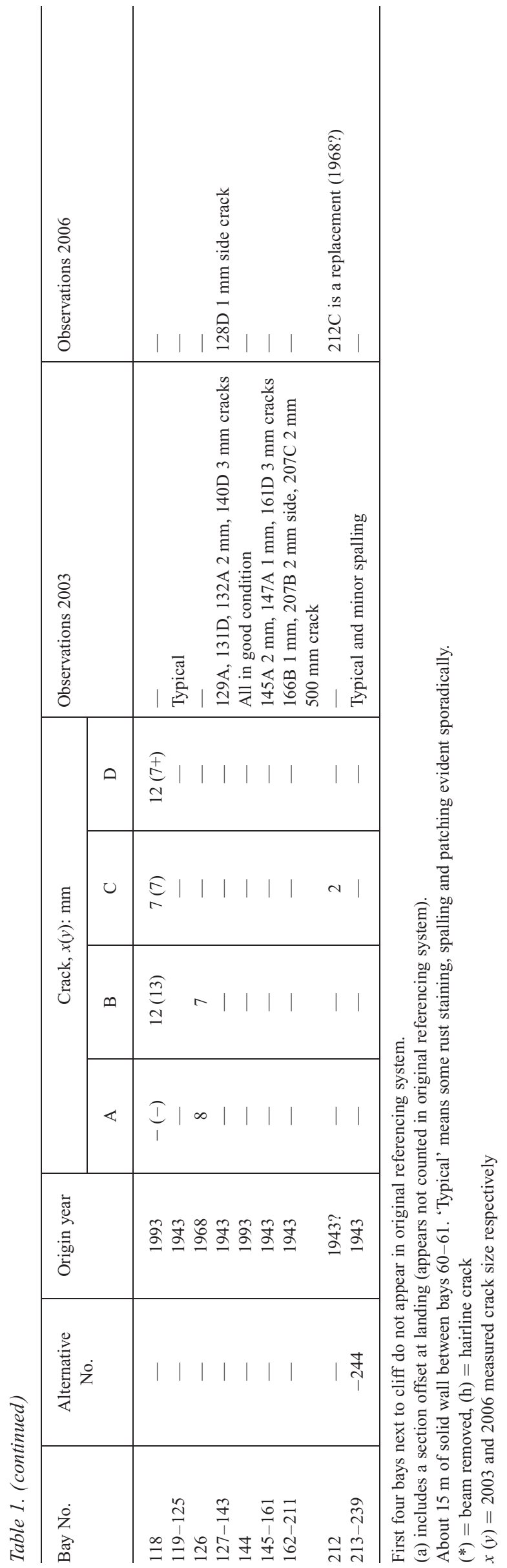

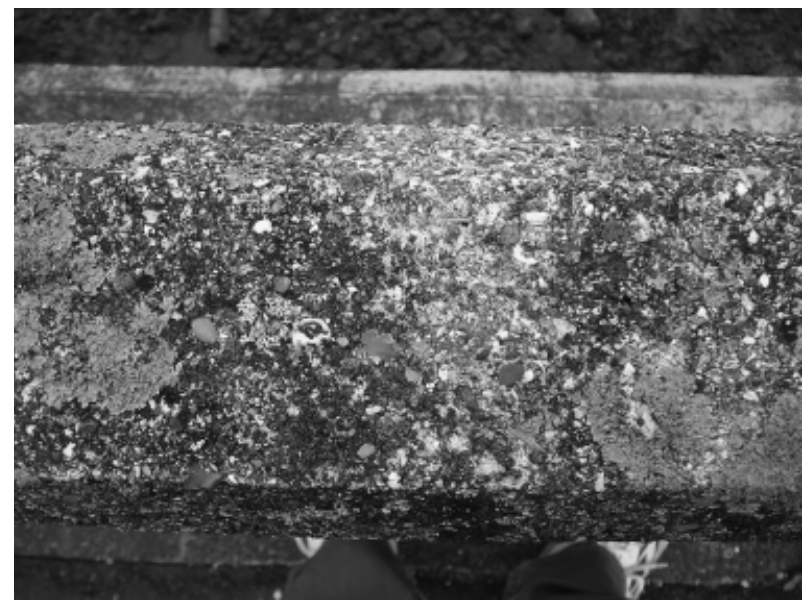

(a)

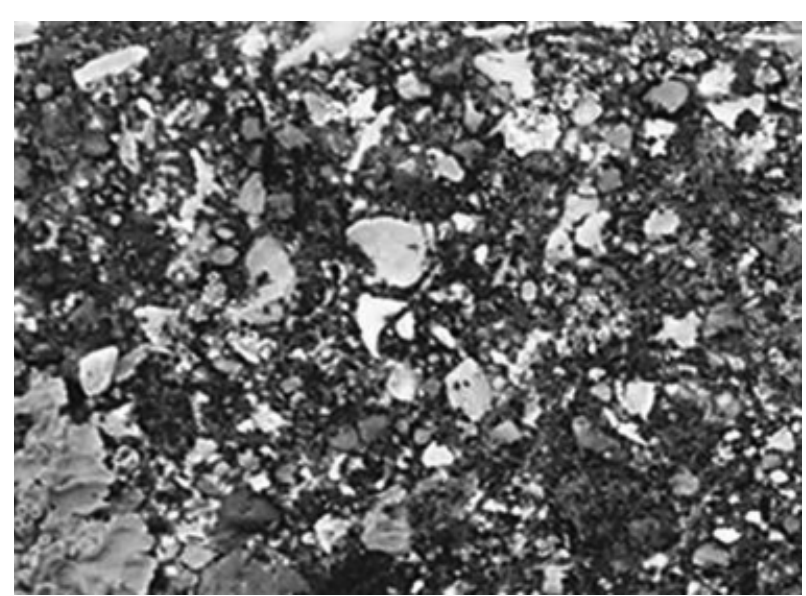

(b)

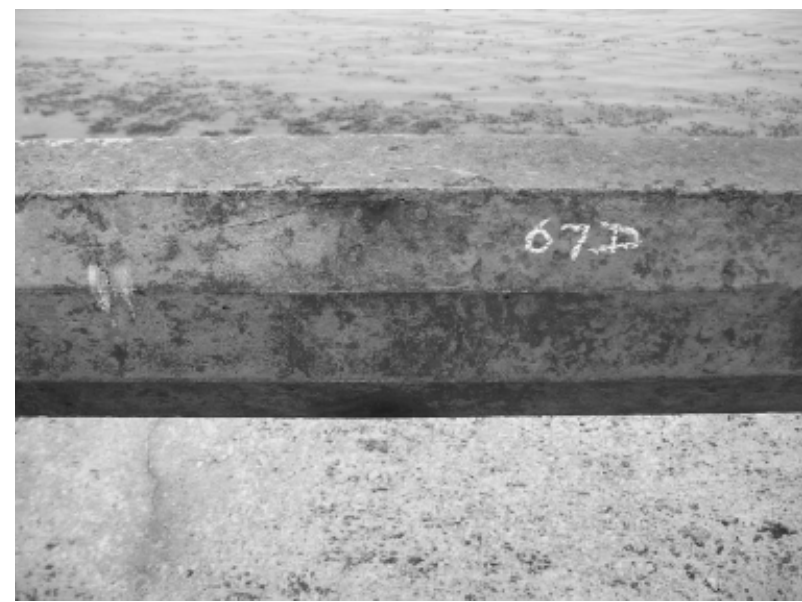

(c)

Fig. 4. Typical condition and surface roughness of (a) 1943, (b) 1943 (detail view) and (c) 1993 concrete railing beams

The estimation of overall failure rates is complicated, however, by the likelihood that in the 1968 and 1993 replacement programmes, replacement inevitably involved discarding some beams still in good condition in any promenade section that contained one or more failed beams. This is likely to have occurred simply for ease of reconstruction. Owing to the unavailability of 


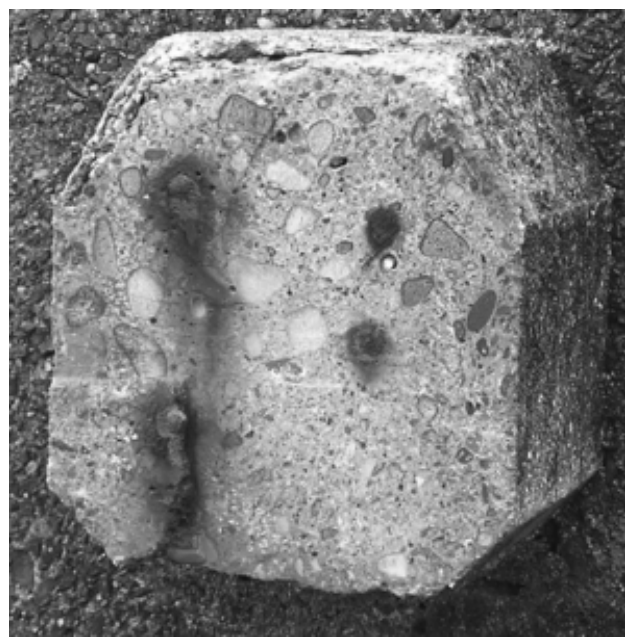

(a)

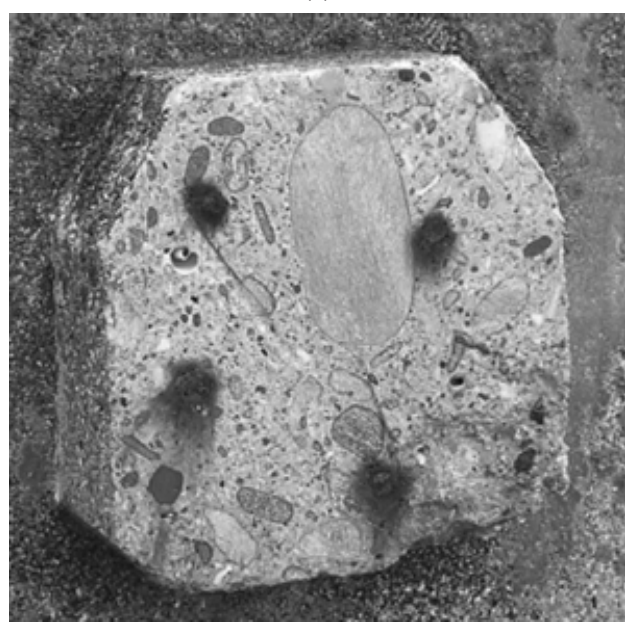

(b)

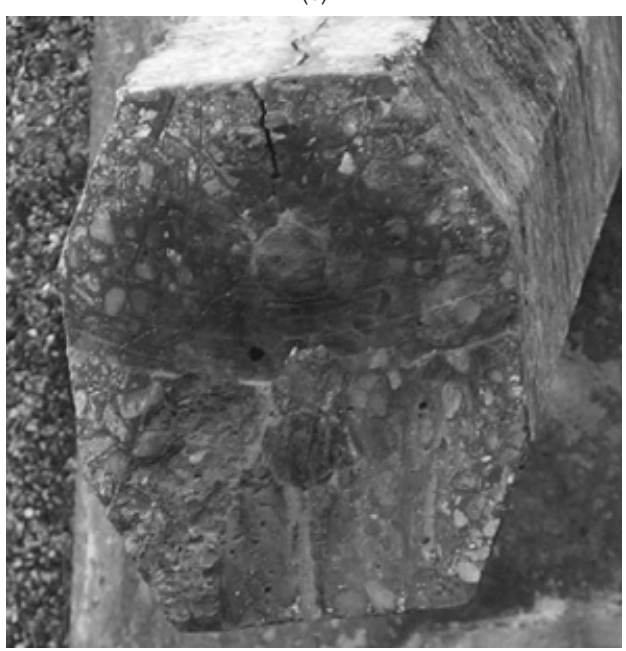

(c)

Fig. 5. (a, b) Samples of cross-section of the 1943 railing beams exposed by removal of the rest of the railing. The rust staining is that resulting from these surfaces being exposed less than 2 years before these photographs were taken. Note the very large range in aggregate sizes and the poor actual location of reinforcing bars. (c) Typical cross-section of a 1993 railing beam showing some vertical cracking and the location and size of the reinforcing bars. Note the good grading of the concrete aggregate. The rust staining is the result of these surfaces being exposed by cutting at some (unknown) time up to 2 years before these photographs were taken

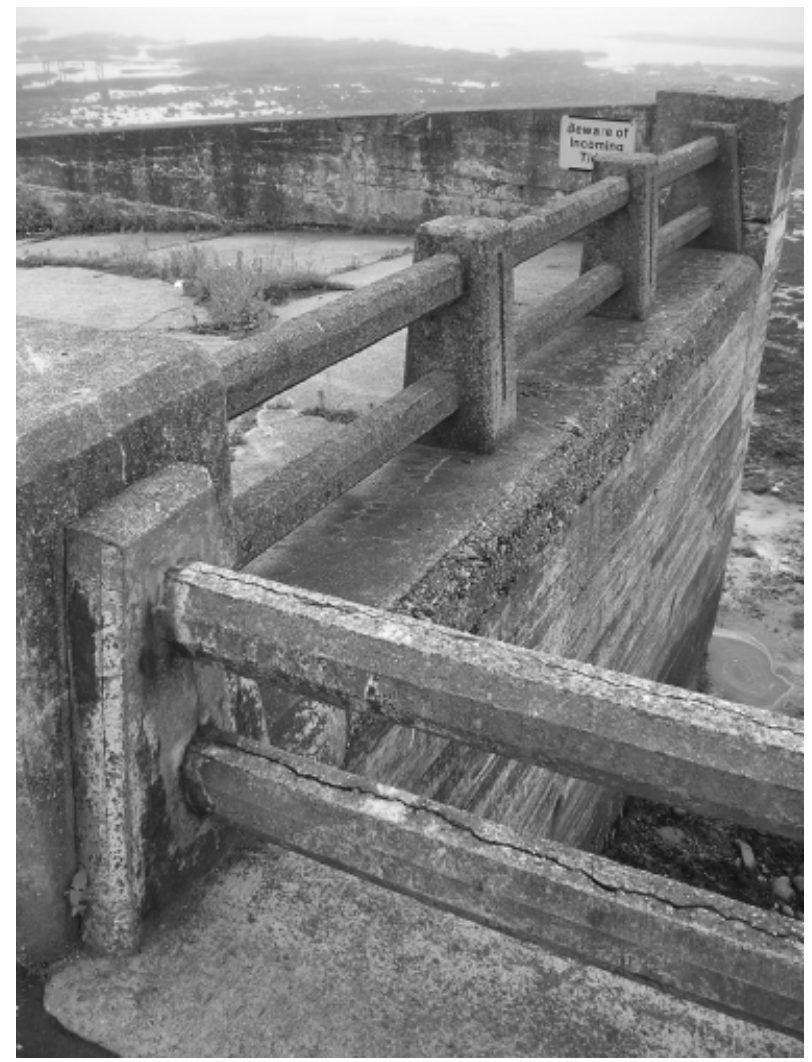

(a)

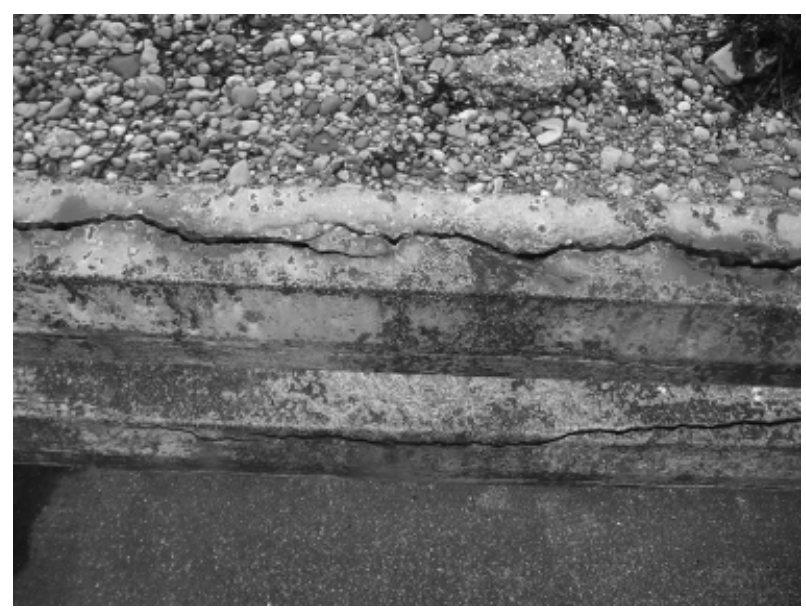

(b)

Fig. 6. (a) View of both typical cracking in 1993 railing beams (front) and uncracked 1943 railing beams (back) near the northern (headland) end of the promenade railing. Note also the obvious difference in surface texture of the railing beams. The front railing beams can be identified as replacements by the patching in the support post at the beam ends. (b) Typical crack pattern in 1993 railing beams viewed from above

historical records, the extent to which this occurred in 1968 and in 1993 can only be estimated.

Figure 10 shows the integrated loss against exposure period relationship that may be developed from the above information. The dotted lines show the assumed, conventionally accepted bi-linear damage model (e.g. Reference 1) of the replacement beams before their

Magazine of Concrete Research, 2009, 61, No. 4 
Table 2. Rebound hammer results

\begin{tabular}{l|c|c|c}
\hline \multirow{2}{*}{ Position } & \multicolumn{3}{|c}{ Construction } \\
\cline { 2 - 4 } & 1943 & 1968 & 1993 \\
\hline 1 (mean of 10 tests) & $41 \cdot 1$ & $47 \cdot 4$ & $42 \cdot 5$ \\
2 (mean of 10 tests) & $38 \cdot 4$ & $47 \cdot 0$ & $41 \cdot 4$ \\
3 (mean of 10 tests) & $42 \cdot 1$ & $47 \cdot 4$ & $38 \cdot 4$ \\
Average & $40 \cdot 5$ & $47 \cdot 2$ & $40 \cdot 7$ \\
\hline
\end{tabular}
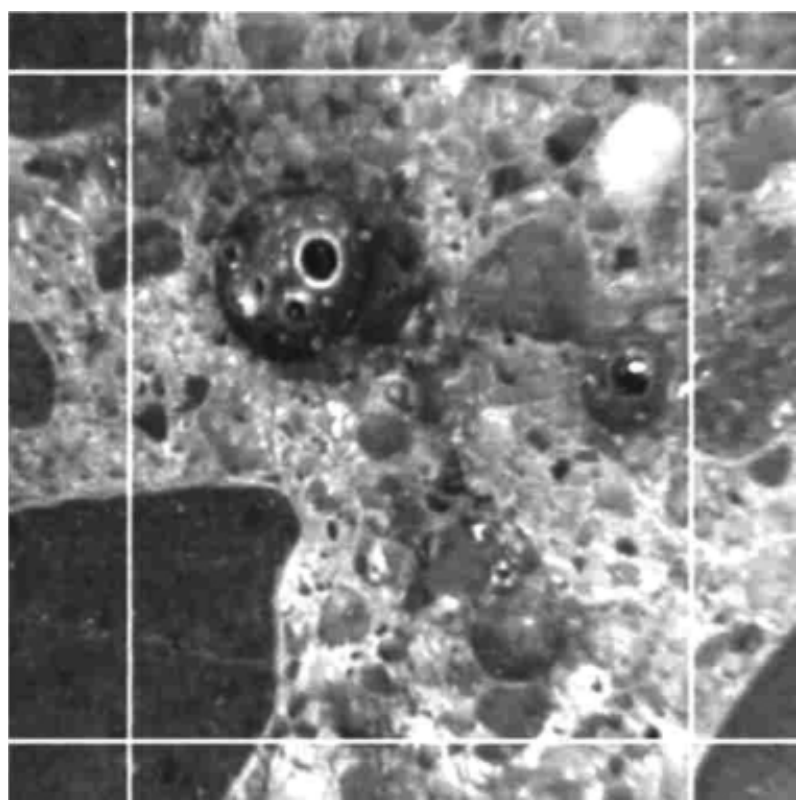

Fig. 7. Micrograph of a typical section of concrete in the 1993 beams. The imposed grid is $10 \mathrm{~mm}$. A resin was used to reveal more clearly the cracks, voids and aggregate. The image has been modified to give greater intensity and contrast. It shows a high degree of good cement bond

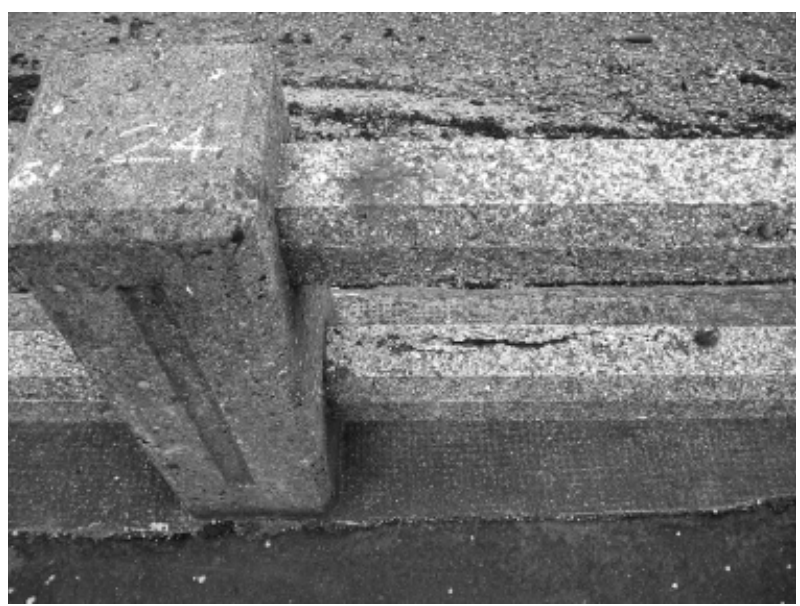

Fig. 8. Typical concrete cover rust staining (top) and spalling (lower) observed for 1943 beams

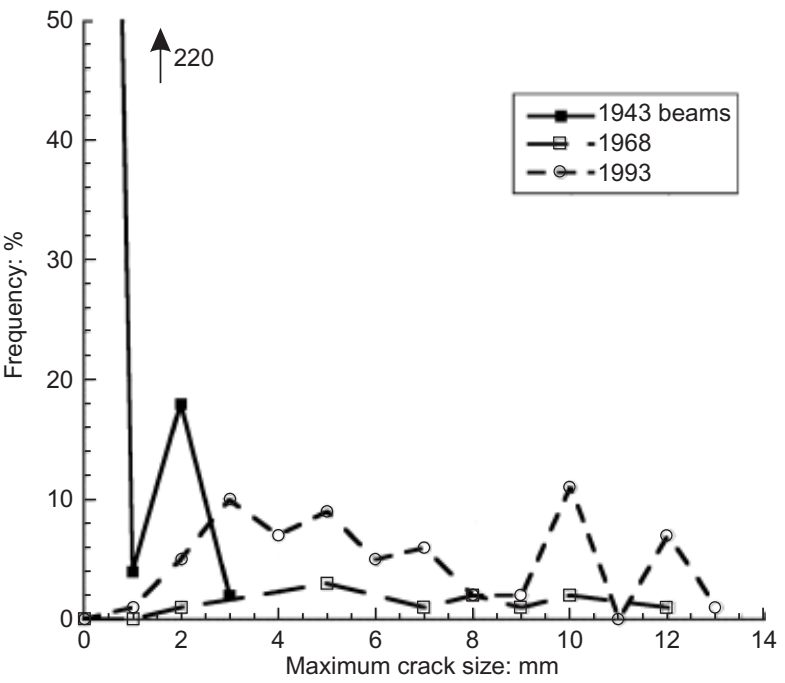

Fig. 9. Frequency of maximum crack size by railing sections for each of the three populations at 2006. Note that there is some artificial variability due to the usual preference in measurements for discrete sizes

behaviour is added into the overall behaviour pattern. A similar behaviour pattern is assumed for the 1943 beams. Owing to lack of data, the commencement of damage for the 1943 beams is assumed to occur in 1963 - that is, some 20 years after first exposure, consistent with the indicative, conventional expectation for chloride-exposed concrete. ${ }^{14}$

In Fig. 10 point $A$ denotes the shift in estimated overall damage following the removal of one or more sections (each consisting of four beams), even though not all beams in that section had failed. Part of the spike at point $\mathrm{B}$ denotes the effect that not all beams from 1968 would have failed by 1993 even though it is likely that some of these were replaced. The actual number is not known but it may be estimated from the total number of sections (2) from 1968 remaining in 2006.

As noted, replacement of promenade railing sections in 1993 is likely to have led to replacement of some 1943 beams that had not yet failed. This is indicated by the vertical spikes, representing both genuine replacements for failed 1943 beam elements and the artificial increase caused by replacement of some of the sound 1943 beams for ease of construction. As noted, it is reasonable to assume that at the end of the replacement programme in 1993, no defective beams remained.

The rate of loss represented by a-a in Fig. 10 is the sum of the rate of loss for the 1943 and the 1968 beams in the period 1993-2006. The total loss during this period includes that for the 1993 beams (shown by dotted lines) and is extended to 2008. After this, only the loss rate due to the 1943 and 1993 beams is relevant and after 2010 only the 1943 loss rate applies. This extrapolated loss is $0 \cdot 2 \%$ based on the rate of loss of 1943 beams in the period 1993-2006. 


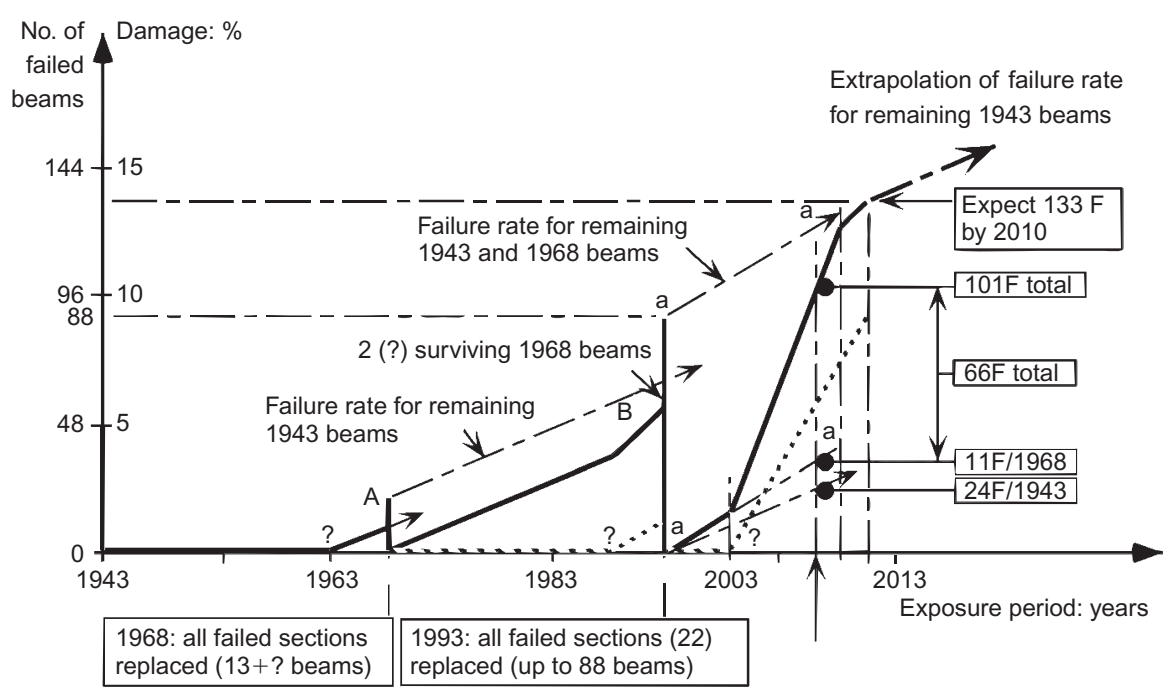

Fig. 10. Number of failed concrete beams owing to corrosion as a function of exposure period for each of the 1943, 1968 and 1993 beam elements and for the combined total showing also the inferred replacement losses. The heavy line is the inferred total loss pattern with time. The dotted lines show the likely bi-linear loss behaviour of the replacement beams. The information in boxes represents data from field observations. The vertical lines represent periods of replacement of beam elements taken as having failed at that time, including those not failed but replaced for reconstruction reasons. F denotes 'failures'

\section{Chloride profiles}

For each of the three concretes, chloride profiles were obtained by the usual method of drilling and extracting dust samples at $10 \mathrm{~mm}$ intervals (commencing at $20 \mathrm{~mm}$ ) in from the exterior concrete surfaces. The dust samples were tested by X-ray fluorescence (XRF) spectroscopy in the laboratory using standard procedures. ${ }^{15}$ The chloride ingress profiles are shown in Fig. 11. They are generally consistent with those obtained by others for similar exposure conditions. ${ }^{16}$

As expected, the chloride content in each case decreases with distance from the exterior concrete surface. The chlorides have penetrated furthest into the concrete body for the 1943 concrete, as expected given

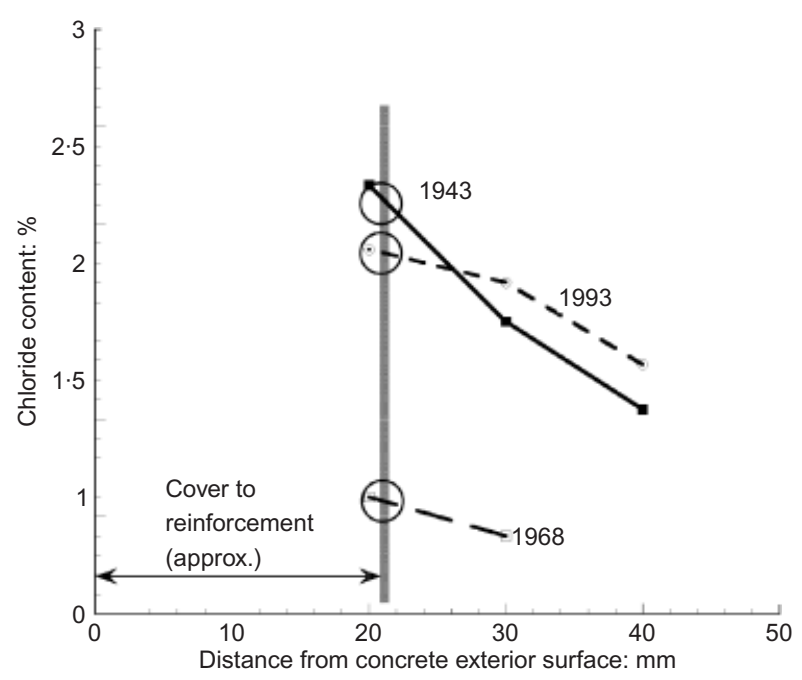

Fig. 11. Typical chloride profiles for each of the 1943, 1968 and 1993 beams showing the relevant minimum concrete cover and the likely chloride level at the reinforcement (as a percentage of total mass) the long period of exposure. The chloride level at the reinforcement for the 1993 concrete is, however, also high-much higher than might be expected for the relatively short duration of exposure (13 years). Although this concrete is air-entrained, it does not follow that it is necessarily permeable since air-entrainment usually is considered to produce air-bubbles rather than continuous pores. ${ }^{17}$

The chloride content at the bars was in each case determined as a percentage of the total concrete mass rather than as a percentage of the cement content. The latter is not known for any of the concretes. A conservative estimate may be made, however, by assuming that the cement content of a concrete mix might vary between 10 and $20 \%$. This means that the vertical axis needs to be multiplied by $5-10$ to obtain the percentage of chlorides relative to cement. Evidently, this shows that the chloride content for each of the beams is much greater than the generally accepted range $(0 \cdot 4-$ $0.6 \%$ ) of chloride contents relative to cement to initiate corrosion. In this context it is of considerable interest that while for the 1943 beams the chloride concentration at the reinforcement bars is high; these beams also have shown excellent long-term reinforcement corrosion behaviour.

\section{Concrete resistivity}

Concrete resistivity is often used as an indicator of the ease with which reinforcement corrosion can occur, with lower concrete resistivity associated with higher rates of corrosion. Four probe electrical resistivity measurements were made using standard procedures at three equi-spaced locations along samples of the var- 
ious beams. The results shown in Table 3 are the averages of multiple readings with typical variability less than 10\%. Evidently the 1993 beams have lower electrical resistance than both the 1968 and the 1943 beams. This indicates that they would have corroded at a faster rate once active corrosion had commenced that is, some (usually considerable) time after corrosion initiation. Typically, resistivities greater than 20 kiloohms are assumed to imply very low corrosion rates while $10-20$ kilo-ohms is taken as associated with low to moderate corrosion rates.

\section{Discussion}

Given the usual assumption of the bi-linear damage model for representing the progression of corrosion damage with time in reinforced concrete structures, it should be expected that both the 1968 and the 1993 beams display a range of crack sizes. As is well known, according to the model, damage is assumed to be a linear function of time after the commencement of active corrosion and reinforcement corrosion. As cracking is the usual form of damage it would be expected that crack size also would increase steadily with increased reinforcement corrosion. This expectation is not borne out by the data, even for the 1993 beams that is, the population with the largest number of cracked beams. One possibility is that the bi-linear damage model is not correct. In fact, recently it has been proposed that the corrosion propagation stage of reinforcement corrosion is much more complex than indicated by this model. ${ }^{1}$

Table 4 summarises the corrosion loss rate, concrete density and resistivity and chloride profile results. It shows clearly that while the 1943 beams have survived much longer than the later beams, this is not consistent

Table 3. Resistivity measurements: kilo-ohms

\begin{tabular}{l|r|r|r}
\hline & 1943 & 1968 & 1993 \\
\hline Position 1 & $306 \cdot 2$ & $68 \cdot 5$ & $13 \cdot 6$ \\
Position 2: centre & $37 \cdot 6$ & $78 \cdot 2$ & $14 \cdot 0$ \\
Position 3 & $338 \cdot 3$ & $114 \cdot 1$ & $12 \cdot 8$ \\
\hline
\end{tabular}

with their apparently lower or similar density and lower or similar permeability compared with the 1993 beams (Table 4). According to the conventional wisdom the chloride concentrations at the surface of reinforcement should be greater for the 1943 beams given also their much longer exposure period to the chloride environment. Fig. 11, however, shows only marginal differences in the chloride profiles-differences that easily could be attributed to experimental error. According to the conventional understanding of chloride penetration and corrosion activation, ${ }^{2}$ the 1943 beams should have failed much earlier, relatively, to their later replacements. The statistics indicate clearly that this is not the case. This is illustrated also in the loss-time profile (Fig. 10). The only measure that is consistent with the loss rates of the 1943 and 1993 beams is the concrete resistivity readings. These are, however, obviously inconsistent with the readings for concrete density, which should correlate with concrete resistivity as the exposure conditions for all beams were and remain essentially similar.

It is interesting to note that similar inconsistencies have been reported by others. Thus Lukas ${ }^{3}$ reported long service lives for road bridges in Austria despite harsh exposure conditions and heavy use of de-icing salts. Recently Lau et $a l .{ }^{4}$ reported that most of more than 1000 reinforced concrete cylinder bridge piles exposed in the marine tidal zone in southern Florida show little sign of reinforcement corrosion, despite around 40 years of exposure and only about $23-40 \mathrm{~mm}$ concrete cover. They noted that this was a 'striking' difference compared with the performance of some other conventional reinforced concrete marine substructures. Similar to the observations for the more than 60year-old Arbroath beams, they noted high levels of chlorides at the reinforcing bars after 40 years' exposure, but this resulted only in minor rust staining and little evidence of preferential chloride penetration along cracks.

There have been suggestions that changes to cementmaking practice that occurred in the UK during the 1960s could be a factor in concrete durability and hence perhaps also in the severity of reinforcement corrosion. ${ }^{18}$ Similarly, there may have been changes in concrete construction practice, but without records of

Table 4. Overview of consistency between corrosion and physical properties

\begin{tabular}{l|c|c|l|l|l|l}
\hline & $\begin{array}{c}\text { Corrosion loss } \\
\text { rate*: \% }\end{array}$ & $\begin{array}{c}\text { Minimum cover: } \\
\text { mm }\end{array}$ & $\begin{array}{l}\text { Superficial concrete } \\
\text { density }\end{array}$ & Rebound hammer & Chloride profile & $\begin{array}{l}\text { Concrete } \\
\text { resistivity }\end{array}$ \\
\hline 1943 & $\leqslant 0.16$ & $20-25$ & Medium-good & Medium & High & $\begin{array}{l}\text { Deep } \\
1 / 3 \text { of others } \\
\text { Deep }\end{array}$ \\
1968 & $\sim 2 \cdot 3$ & $20-25$ & Good & Medium & Low \\
1993 & $\sim 5 \cdot 8$ & $20-25$ & Good & high \\
\hline
\end{tabular}

*Proportion of beams failed per unit time of exposure

${ }^{\dagger}$ Subjective interpretation

\$Subjective assessment of relative scales (see text)

${ }^{\S}$ From polarisation resistance 
the specifications and the construction of the 1943 and the 1968 concretes used in the Arbroath balustrade, it is difficult to be sure. What can be said is that for the UK generally the changes in cement making were considered to have negligible influence on durability owing to the very small changes in cement composition. ${ }^{19}$ There is also no strong evidence to support a case for significant changes in concrete-making practice over the period of interest (1943-1993) other than the airentrainment issue already noted.

Clearly there are matters here for exploration and for further research, despite the view in many quarters that the corrosion of reinforcing bars in concrete is well understood and that its control involves mainly the achievement of good-quality concrete and high resistance to chloride diffusion. ${ }^{11}$ The observations herein, together with those reported by others, ${ }^{3,4}$ all for long-term field observations, clearly indicate that chloride penetration to the reinforcing bars may not necessarily be indicative of the initiation of active corrosion and, even less likely, of its rate. The conventional view, that to achieve greater durability of reinforcing bars it is necessary to have greater and/or denser concrete cover, is not supported both by the present observations and those for the Florida piers. What influences should be considered and which aspects are important in the initiation and progression of reinforcement corrosion appear, therefore, to be still open questions. They point, clearly, to there being a requirement for much more fundamental research into the precise mechanics and causes of reinforcement corrosion.

Because the reinforced concrete balustrade at Arbroath consists of so many nominally identical and completely independent elements, all exposed to essentially the same harsh marine environment, it is essentially an experimental test rig, which, in other circumstances, would cost a great deal to set up and maintain. The balustrade already has provided a rare opportunity for research into the long-term (60+ years) corrosion behaviour of reinforced concrete under actual exposure conditions. With goodwill and good management the Arbroath balustrade could continue in this role as well as fulfilling its primary function. In could provide extremely useful information since there is very little objective information about the behaviour of reinforced concrete for long periods - that is, much in excess of 60 years. This would require the existing structure to be kept in service for many years into the future, periodically being monitored and examined in detail, and with only failed beam elements being replaced to ensure public safety. Ideally the replacement beams would be made to modern design standards and also subject to monitoring and examination. Evidently, each such replaced beam element essentially represents an independent experimental sample. At present there are no known similar long-term observation sites for marine atmospheric exposure of reinforced concrete anywhere in the world: the Arbroath site presents a unique opportunity.

\section{Conclusions}

Despite having been exposed to a harsh sea-spray environment for over 63 years, the great majority of the reinforced concrete promenade railing elements constructed around 1943 show little evidence of reinforcement corrosion. In contrast, the elements constructed more recently $(1968,1993)$ show very serious reinforcement corrosion and extensive and wide longitudinal cracking of the surrounding concrete.

The higher corrosion resistance of the 1943 concrete is generally consistent with the concrete electrical resistivity measurements. They are not, however, consistent with the concrete density (rebound hammer) measurements. The degree of corrosion of the reinforcing bars was found to be inconsistent with chloride penetration measurements. Chloride penetration for the badly corroded 1968 beams was found to be lower than that for similarly badly corroded 1993 beams. In contrast, the chloride penetration at the reinforcement for the 1993 and for the 1943 beams was similar, despite the very much lower corrosion damage of the 1943 beams.

Overall, these observations are inconsistent with the usual understanding of the role of chloride concentration and corrosion propagation and suggest that more detailed research is required to improve understanding of the role of chloride in the long-term corrosion of reinforcement bars.

\section{Acknowledgements}

This work was commenced while the first author was an Engineering Physical Sciences Research Council (EPSRC) Visiting Fellow at the University of Dundee in 2003. The support of the EPSRC (EP/E00444X/ 01) and the Australian Research Council is appreciated. Mr McCoughlan performed the 2004 field survey and carried out some testing as part of a final year Honours project at the University of Dundee.

\section{References}

1. Melchers R. E. and Li C. Q. Phenomenological modelling of corrosion loss of steel reinforcement in marine environments. ACI Materials Journal, 2006, 103, No. 1, 25-32.

2. Bentur A., Diamond S. and Berke N. S. Steel Corrosion in Concrete: Fundamentals and Civil Engineering Practice. E\&FN Spon, London, 1997.

3. LukAs W. Relationship between chloride content in concrete and corrosion in untensioned reinforcement on Austrian bridges and concrete road surfacings. Betonwerk und Fertigteil-Technik, 1985, 11, 730-734.

4. Lau K., Sagues A. A., Yao L. and Powers R. G. Corrosion performance of concrete cylinder piles. Corrosion, 2007, 63, No. 4, 366-378.

5. Francois R. and Maso J. C. Effect of damage in reinforced concrete on carbonation or chloride penetration. Cement and Concrete Research, 1988, 18, No. 6, 961-970.

6. LI C. Q. Initiation of chloride induced reinforcement corrosion 
in concrete structural members: prediction. ACI Structures Journal, 2002, 99, No. 2, 133-141.

7. Poupard O., L'Hostis V., Catinaud S. and Petre-Lazar I. Corrosion damage diagnosis of a reinforced concrete beam after 40 years natural exposure in marine environment. Cement and Concrete Research, 2006, 36, No. 3, 504-520.

8. Liam K. C., Roy S. K. and Northwood D. O. Chloride ingress measurements and corrosion potential mapping study of a 24year-old reinforced concrete jetty structure in a tropical marine environment. Magazine of Concrete Research, 1992, 44, No. $160,205-215$.

9. Weibenga J. G. Durability of Concrete Structures Along the North Sea Coast of the Netherlands. American Concrete Institute, Detroit, 1980, pp. 437-452. Special Publication SP65.

10. GJoRV O. E. and Kashino N. Durability of a 60 -year-old reinforced concrete pier in Oslo Harbor. Materials Performance, 1986, 25, No. 2, 18-26.

11. Polder R. B. and de Roor M. R. Durability of marine concrete structures: field investigations and modelling. Heron, 2005, 50, No. 3, 133-153.

12. Neville A. M. Properties of Concrete, 4 th edn. Wiley, Chichester, 2006.
13. Bamforth P. B. An enduring problem. Concrete Engineering International, 1999, 3, No. 8, 28-31.

14. Bamforth P. B., Price W. F. and Emerson M. An International Review of Chloride Ingress into Structural Concrete. TRL Scotland, 1997, TRL Contractor Report 359.

15. VAN Grieken R. E. and MarkowicZ A. A Handbook of X-ray Spectrometry: Methods and Techniques. Marcel Dekker, New York, 1993.

16. Roy S. K., Liam K. C. and Northwood D. O. Chloride ingress in concrete as measured by field exposure tests in the atmospheric, tidal and submerged zones of a tropical marine environment. Cement and Concrete Research, 1993, 23, No. 6, 12891306.

17. Powers T. C. Properties of Fresh Concrete. Wiley, New York, 1969.

18. CoRISH A. T. and JACKSON P. J. Portland cement properties: past and present. Concrete, 1982, 16, No. 7, 16-18.

19. Nixon P. J. and Spooner D. C. Concrete proof for British cement. Concrete, 1993, 27, No. 5, 41-44.

Discussion contributions on this paper should reach the editor by 1 November 2009 